\title{
Current Management of Gastric Varices
}

\author{
Maruyama $\mathrm{H}^{1}$ Yokosuka $\mathrm{O}^{1}$ \\ 'Department of Medicine and Clinical Oncology, Chiba University Graduate School of Medicine, Japan.
}

\begin{abstract}
Gastric varices are a major hemodynamic feature in patients with portal hypertension. Its incidence as well as bleeding rate is lower than that of esophageal varices. However, rupture of gastric varices sometimes results in very serious consequences in the clinical course and its management is very important. Recent developments in imaging technology have made it possible to evaluate the portal hemodynamics in detail by less invasive procedure. Furthermore, advancements in medical instruments and technologies have led to the development of endoscopic ligation devices, interventional radiology techniques like transjugular intrahepatic portosystemic shunt and balloon-occluded retrograde transvenous obliteration, and skills in surgical treatments. This overview will focus on the classification, pathophysiology, current management of gastric varices, and treatments in patient with portal hypertension.
\end{abstract}

Key words: Gastric fundal varices, Hemodynamics, Interventional radiology techniques, Portal hypertension.

\section{INTRODUCTION}

Gastric varices (GV) are a hemodynamic feature of major potential consequence in patients with portal hypertension. ${ }^{1}$ Sarin et al. has reported that $20 \%$ of patients with portal hypertension had GV, $27 \%$ in bleeders and $4 \%$ in non-bleeders. ${ }^{2}$ According to the study of 1392 cirrhotic patients by endoscopic examination by Kim et al, 57\% (793) patients had esophageal varices (EV), 25\% (349) patients had GV, and $18.2 \%$ (253) patients had both. ${ }^{3}$ Although lower bleeding rates of GV than those of EV have been reported, rupture from GV sometimes results in serious consequences in the clinical course. ${ }^{4,5}$ Variceal hemorrhage is a major cause of mortality in cirrhotic patients with portal hypertension. ${ }^{6}$

Various techniques like endoscopic, surgical and techniques using interventional radiology are available for the treatment of GV. However, no definitive guidelines regarding prophylactic treatment for $\mathrm{GV}$ are yet to be established so far. As a result the application of GV treatments means control of acute bleeding or following treatment in elective cases. Endoscopy is an effective tool for attaining hemostasis in the majority of emergency bleeding cases, even if the effects are not always sufficient as a curative treatment method. Because they are less invasive than surgery and are becoming wellestablished procedures with efficient therapeutic effect, newer interventional techniques may now play the principal role in the management of GV. This overview will focus on the current management of GV, classification, pathophysiology and treatments in patient with portal hypertension.

\author{
Correspondence: \\ Hitoshi Maruyama \\ 1-8-1, Inohana, Chuou-ku, Chiba \\ 260-8670, Japan. \\ Email: maru-cib@umin.ac.jp
}




\section{Diagnosis and classification of GV}

There are different classifications for $\mathrm{GV}{ }^{7}$ A simple approach proposed by Sarin et al. is one of the most well known for presenting the features of GV. ${ }^{2}$ They classified GV into gastroesophageal varices (GOV; GOV1 and GOV2) and isolated gastric varices (IGV; IGV1 and IGV2). They stated that the most common type was GOV1, accounting for $74 \%$ of all GV, with the incidence of the others being $16 \%$ for GOV2, $8 \%$ for IGV1, and $2 \%$ for IGV2. Although this classification is easy to use, IGV1 type varices (gastric fundal varices) accompanied by EV might not be clearly categorized by this classification. Kim et al. reported that gastric fundal varices were found in $41 \%(143 / 349)$ of consecutive GV patients, and the others had varices in the cardia ${ }^{3}$.

The Japanese classification is based on location, form, color, and the presence of red color sign on the varices, and F2 (moderate) or F3 (severe) form, blue color varices, red color sign on the variceal surface are considered to be risky signs for variceal bleeding. ${ }^{8}$ Although this classification has much more information than that of Sarin et al., it may be rather complicated for practical use. In addition, endoscopic predictive signs for GV bleeding have not been fully clarified yet. Alternatively $\mathrm{GV}$ is also classified into two groups, primary and secondary GV. ${ }^{4}$ Primary GV are naturally developed varices, and secondary GV develop after the endoscopic treatment of EV. The incidence of the latter type of varices is reported to be $9 \% .^{2}$ Establishment of an alternative classification, which would be widely acceptable, is awaited for the management of $\mathrm{GV}$.

\section{Sinistral portal hypertension (segmental PHT, left-sided PHT)}

Occlusion or stenosis of splenic vein is a main cause for sinistral portal hypertension, which often results in IGV 1 or IGV2. 2,9-11 The natural history of IGV2 and its bleeding risk have not been fully examined. Splenectomy or partial splenic embolism is recommended for the treatment of IGV2. 9, 10,12,13 The effectiveness of stenting for stenotic or obstructed splenic vein has not been established yet.

\section{Anatomy and hemodynamics of GV}

The principal position of varices in the gastrointestinal wall is different between EV and gastric fundal varices. Esophageal varices form in the lamina propria mucosa and submucosa while gastric fundal varices form deeply in the submucosa. ${ }^{14}$

The collateral vessels supplying blood flow for varices develop as a result of portal hypertension. The hepatofugal

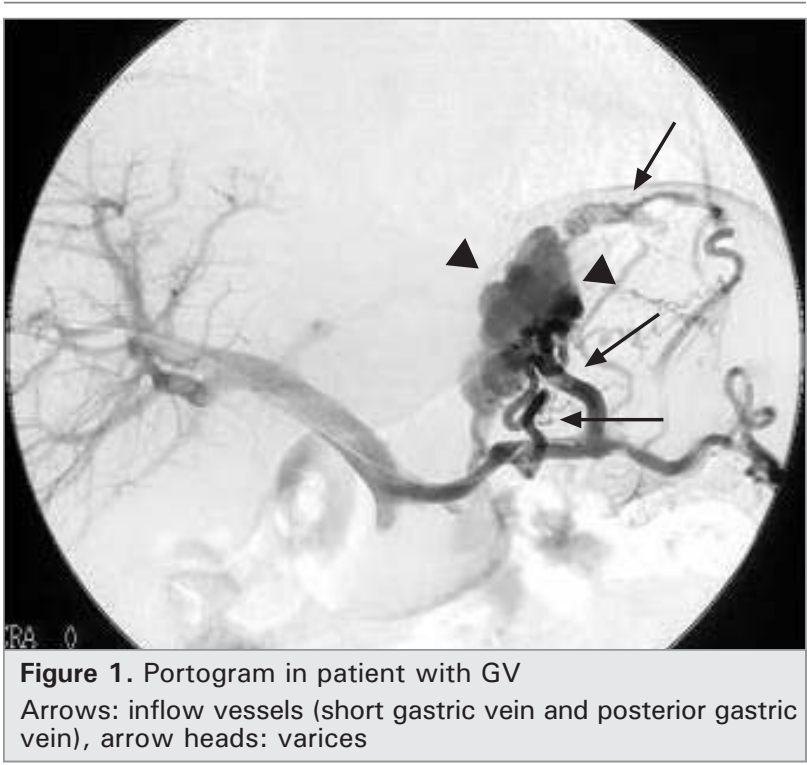

blood flow in the left gastric vein (LGV) drains into the cardia and distal esophagus, and it is a main supplying route for EV or GOV1. ${ }^{15-17}$ Short gastric vein (SGV) and/or posterior gastric vein (PGV) are known as major inflow routes for gastric fundal varices (Fig. 1). ${ }^{18,19}$ According to the study by Watanabe et al., over $50 \%$ of gastric fundal varices have SGV and/or PGV dominant blood supply on portogram. As for the outflow routes, the main pathway of EV is azygos vessel, while that of the majority of gastric fundal varices is the gastrorenal shunt (GRS). It is reported that over $80 \%$ patients with gastric fundal varices have GRS for their drainage route, and that the diameter of GRS depends on the severity of the gastric fundal varices. ${ }^{18}$ Application of the appropriate treatment method may be closely related to these anatomical and hemodynamic differences between EV and fundal GV.

Watanabe et al. measured portal venous pressure (PVP) in 230 patients with EV and/or gastric fundal varices, and found that PVP was significantly higher in EV patients (326 \pm 66 ) than in patients with gastric fundal varices (240 \pm 37 ), and PVP in patients with gastric fundal varices decreased according to the development of GRS. ${ }^{1}$ Another study reported that patients with large gastric fundal varices have lower portal pressure than those with EV, which may be a result of the development of gastro-renal porto-systemic shunts. ${ }^{20}$ According to the study by Tripathi et al, GV bleeding accounts for many more cases in bleeding patients with a pre-transjugular intrahepatic portosystemic stent shunt (TIPSS) portal pressure gradient of -'3d $12 \mathrm{mmHg} .{ }^{21}$ They also added that it is not clear why patients bleed at a portal pressure of $<12 \mathrm{mmHg}$ and other factors such as the presence 
of red spots, variceal size and that of underlying gastritis may be important. These results may suggest that GV bleeding is not always caused by high PVP. Further studies are needed to clarify the clinical pathophysiology of GV bleeding.

Clinical presentation and natural history of GV Bleeding is the most important clinical presentation in GV patients. Previous reports showed that the bleeding rate from GV is lower than that from EV, ${ }^{22} 3 \%$ to $5 \%$ by Sarin et al, $^{23} 14-16 \%$ by Teres et al, ${ }^{24}$ and $60 \%$ by Hosking et al. ${ }^{25}$ However, the prediction of the occurrence of $\mathrm{GV}$ bleeding is a critical because the mortality rate in $\mathrm{GV}$ patients without prophylactic treatment is not low. 2,3,26,27 Kim et al. reported that variceal size and redspot appearance on endoscopy, and Child's score were the predictive factors for bleeding from gastric fundal varices, ${ }^{3}$ and a comparable report was reported in another study as well. ${ }^{27}$ However, these risk factors for GV bleeding are too vague without quantitative assessment, and the application of prophylactic treatment for GV has not been established.

According to the clinical study of 145 cirrhotic patients with gastric fundal varices by Akiyoshi et al., the cumulative survival rates at 1,3 , and 5 years were 75 , 53 and $34 \%$, respectively. ${ }^{27}$ The cause of death was related to gastrointestinal hemorrhage, hepatic failure, hepatocellular carcinoma and others. Death related to bleeding from gastric fundal varices was $21 \%$; $4 \%$ in small-sized gastric fundal varices, $21 \%$ in medium-sized ones, and $54 \%$ in large-sized ones. They also added that the presence of HCC and higher Child's score were highly significant prognostic factors. Although bleeding and/or hepatic encephalopathy are two major clinical symptoms in patients with GV, preservation of liver function and control of HCC are essential for the management of GV patients. Some GV patients develop hepatic encephalopathy due to the portosystemic collateral vessel, a gastrorenal shunt. Watanabe et al. reported that portal systemic encephalopathy was more frequent in patients with gastric fundal varices $(25 \%)$ than with EV $(3 \%, p<0.01){ }^{18}$

\section{Management of GV}

\section{Primary prophylaxis of GV bleeding}

There are not enough data that prove the effectiveness of ß-blockers in the primary prevention of GV bleeding. ${ }^{28}$ It is an almost common perception that middle- or largegrade GV are a candidate for receiving balloon-occluded retrograde transvenous obliteration (B-RTO), a simple and safe technique as a primary prophylactic treatment in Japan. However, it has not been accepted in Western countries because of a lack of evidence. Randomized controlled trials would be necessary to prove whether the Japanese way of treatment is acceptable or not.

\section{Endoscopic treatment}

Trudeau et al. mentioned in their clinical studies with 92 patients that the endoscopic injection sclerotherapy (EIS) in patients with bleeding GV offers only temporary control of bleeding, and the high incidence of severe early re-bleeding requires consideration of alternative methods for management or modified sclerotherapy techniques. ${ }^{22}$ Endoscopic intravariceal injection of cyanoacrylate is one of the most common treatment methods for GV bleeding (Fig. 2). Sarin et al. compared the efficacy and safety of sclerotherapy using alcohol and obturation using cyanoacrylate glue in a prospective study in $37 \mathrm{GV}$ patients with portal hypertension. ${ }^{29}$ Cyanoacrylate injection could achieve the arrest of acute GV bleeding more often than alcohol injection in

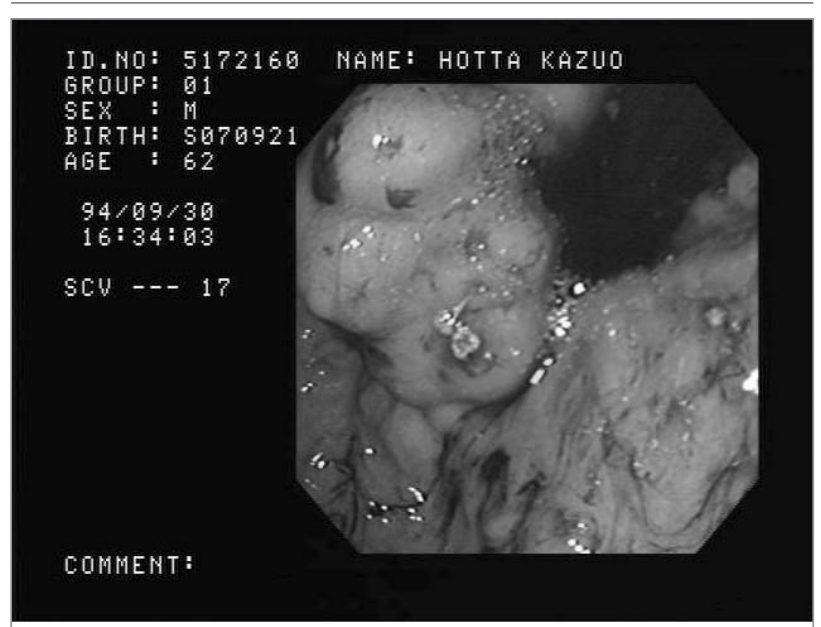

Figure 2a) Just after initial treatment Arrow: Injected cyanoacrylate

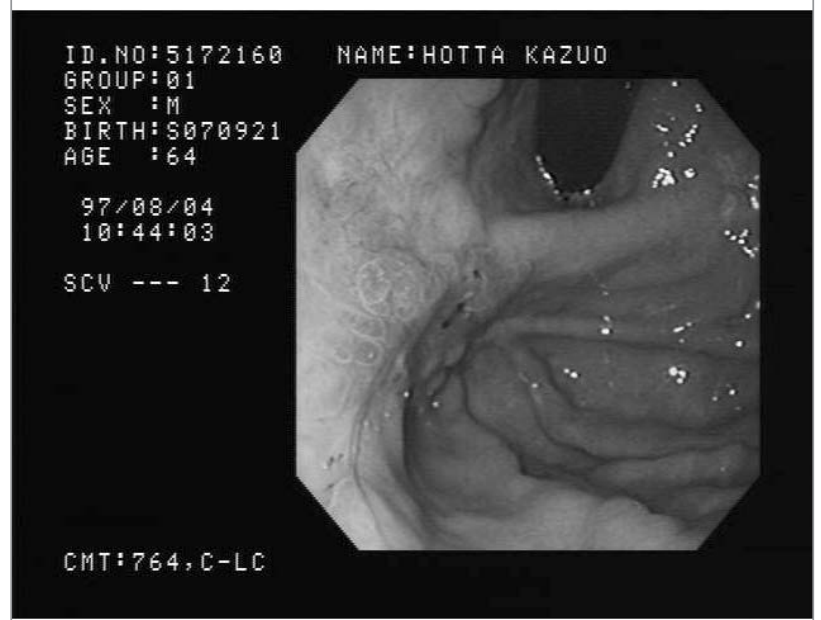

Figure 2b) After five series of endoscopic treatment

Figure 2: EIS for GV in HCV-related cirrhotic patient (bleeding case), 62-year-old male 
their study. Furthermore, variceal obliteration effect was found much more in the sclerotherapy group than in the obturation group, and the period for treatment was significantly shorter in the former group. However, re-bleeding rates of emergency and elective treatment were $25 \%$ and $33 \%$ after alcohol injection, and $22 \%$ and $27 \%$ after cyanoacrylate injection, respectively. Greenwald et al. reported that re-bleeding was seen in $2 / 37(5 \%)$ at 72 hours, $1 / 30(3 \%)$ at 6 weeks and $5 / 28(18 \%)$ at 1 year in 37 cirrhotic patients. ${ }^{30}$ As for the long-term effect of this treatment, Akahoshi et al. followed the clinical course after the endoscopic injection of histoacryl combined with ethanolamine oleate (Grelan Pharmaceutical Co., Ltd., Tokyo, Japan), and mentioned that cumulative non-bleeding rates were $64.7 \%, 52.7 \%$, and $48.2 \%$ at 1,5 , and 10 years after the treatment, respectively. ${ }^{31}$ Further, recurrent bleeding was found in $20 / 50(40 \%)$ in the mean follow-up period of 28.1 months, and $80 \%$ of re-bleeding patients bled within one year after the initial treatment. As these authors mentioned, cyanoacrylate injection is based on a simple technique and is cost-effective. However, the re-bleeding rate is high, and cyanoacrylate injection has the potential for systemic complications caused by the migration of cyanoacrylate into the inferior vena cava (IVC) through a GRS. ${ }^{32}$ Therefore, use of cyanoacrylate injection as a curative treatment is controversial.

Although the ligation method was introduced for esophageal varices, it is in fact also applicable to GV treatment. ${ }^{33}$ Cipolletta et al. reported that emergency ligation with a detachable snare was effective for endoscopic hemostasis of GV bleeding in seven cirrhotic cases. ${ }^{34}$ Shiha et al. examined the efficacy of band ligation method for $\mathrm{GV}$ in 27 patients. They found that hemostasis was obtained in 16/18 (88.8\%) emergency bleeding cases, and re-bleeding was found in 5/27 $(18.5 \%) .{ }^{35}$ However, six patients died $(22.2 \%)$, and the cause of death in $3 / 6$ was recurrent bleeding. Lo et al. compared the efficacy and complications between cyanoacrylate injection method and band ligation method in cirrhotic patients with GV bleeding history, and the re-bleeding rate was significantly higher in the ligation group than in the endoscopic obturation group. ${ }^{36}$ They concluded that endoscopic obturation using cyanoacrylate was more effective and safer than band ligation in the management of $\mathrm{GV}$ bleeding. In any event, band ligation alone may not be sufficient in some cases with GV.

Endoscopic intravariceal injection with bovine thrombin is also a useful treatment method for GV bleeding.
Williams et al. reported that thrombin injection could achieve hemostasis in all 11 patients with GV bleeding (nine with fundal varices and two with high lesser curve varices), and only one patient had re-bled during a median follow-up of nine months. ${ }^{37}$ Przemioslo et al. also reported that initial hemostasis was achieved in 49/52 (94\%) GV patients. ${ }^{38}$ However, they added that the bleeding-related mortality at 72 hours after the index bleed was $3 / 52$ (6\%), 9/49 surviving patients $(18 \%)$ re-bled and one further patient died at six weeks. A control study with a large number of patients may be necessary to confirm the efficacy of this method, and the risk of prion transmission should be excluded.

There are some novel approaches for GV treatment. Yoshida et al. introduced a novel endoscopic treatment method using a detachable snare and simultaneous endoscopic sclerotherapy and band ligation. ${ }^{39}$ This method provided endoscopic disappearance of GV in $97.1 \%$ of the patients, and hemostasis was obtained in all eight emergency cases. They also added that the 2 -year cumulative non-recurrence rate was $85 \%$, the 2 -year cumulative non-bleeding rate was $92 \%$, and the 2 -year cumulative survival was $80 \%$, with no serious short-term complications. In another series a combined endoscopic injection sclerotherapy and endoscopic variceal ligation was found to be effective for the control of acute GV bleeding. ${ }^{40}$ There are high hopes for these ingenious attempts to lead to the improvement of therapeutic results in GV patients.

\section{Interventional technique}

Transjugular intrahepatic portosystemic shunt (TIPS) Transjugular intrahepatic portosystemic shunt is an effective method for decreasing PVP, and many studies have demonstrated its usefulness for secondary prophylaxis of EV bleeding. ${ }^{41}$ As for GV, Stanley et al. followed the clinical course of 106 patients after TIPS, and found that variceal re-bleeding was similar in the EV and GV groups, with no difference in survival rate between the two groups. ${ }^{42}$ Chau et al. reported the efficacy of TIPS for uncontrolled variceal bleeding in 84 cases of EV and 28 cases of GV. ${ }^{43}$ Bleeding was controlled in the majority of patients in both groups, and the re-bleeding rate was $24 \%$ in the EV group and $29 \%$ in the GV group respectively. The mortality was similar both the groups. In a series by Barange et al. the hemostasis was achieved in 18/20 of active bleeding cases of GV patients who were unresponsive to vasoactive agents, sclerotherapy, and/or tamponade and were poor surgical candidates. The re-bleeding rates were $14 \%, 26 \%$, and $31 \%$, respectively, at 1 
month, 6 months, and 1 year. ${ }^{44}$ These results suggest the effectiveness of TIPS in the control of GV bleeding compared with EV bleeding. Nevertheless, the application of TIPS for GV has some controversies. Regarding PVP, Sanyal et al. found that $50 \%(6 / 12)$ of patients undergoing TIPS for prevention of GV re-bleeding failed to decompress the varices, and 4 of the 6 patients had a large GRS and PPG $<12 \mathrm{~mm} \mathrm{Hg} .{ }^{45}$ However, Tripathi et al. reported that TIPS was equally effective in the prevention of re-bleeding following GV and EV bleeding, even though the portal pressure gradient (PPG) was less than $12 \mathrm{~mm} \mathrm{Hg}$ at the time of TIPS. ${ }^{21}$ As opined by Ryan et al. in their letter, it should be proven whether the patients with lower PPG require TIPS or not. ${ }^{46}$ Another article reported that endoscopic cyanoacrylate injection therapy was superior to TIPS in terms of initial re-bleeding rate, hospitalization duration and cost. ${ }^{47}$ Although TIPS appears to be a sensible procedure for portal hypertension, the efficacy of it is still to be proven when re-bleeding and overall survival rates are concerned.

\section{Balloon-occluded retrograde transvenous obliteration} Balloon-occluded retrograde transvenous obliteration (B-RTO) is quite useful for GV embolization (Fig. 3). This technique is based on the balloon occlusion of GRS, a major drainage route of GV in over $80 \%$ of GV patients. ${ }^{18}$ Kanagawa et al. introduced it in 1991 in Japan, ${ }^{48}$ and some technical improvements have been added since then ${ }^{49-52}$ After B-RTO, eradication of GV is obtained in the majority of patients with only minor complications, such as fever, pain and hemoglobinuria, and recurrence is very rare. ${ }^{53-56}$ Ninoi et al. reported that the 1 - and 3-year survival rates were over $90 \%$ and over $70 \%$, respectively, in GV patients after BRTO. ${ }^{57}$

Akahane et al. reported that portal blood flow increased significantly from $5.4 \pm 1.1$ to $7.85 \pm 1.4 \mathrm{~cm} / \mathrm{s}$ and that the indocyanine green (ICG) retention rate improved significantly from $31.8 \pm 16.1$ to $21.8 \pm 12.4 \%$ in GV patients after B-RTO. ${ }^{58}$ However, they also found a significant increase in PVP from $25.4 \pm 7.6$ to $30.7 \pm 5.8$ $\mathrm{mm} \mathrm{H} 2 \mathrm{O}$, as this technique has the opposite effect to a decompressive treatment like TIPS. Thus, the deterioration of EV is important as a long-term complication after B-RTO, and a worsening rate of EV is reported in over $60 \%$ of the patients at 5 years. ${ }^{57}$ Careful follow-up by endoscopy is necessary after BRTO and EVL may be needed in many cases after treatment of GV. Principally B-RTO needs balloon occlusion for the outflow route of $\mathrm{GV}$ and it may not be useful for attaining hemostasis of GV. However, Arai

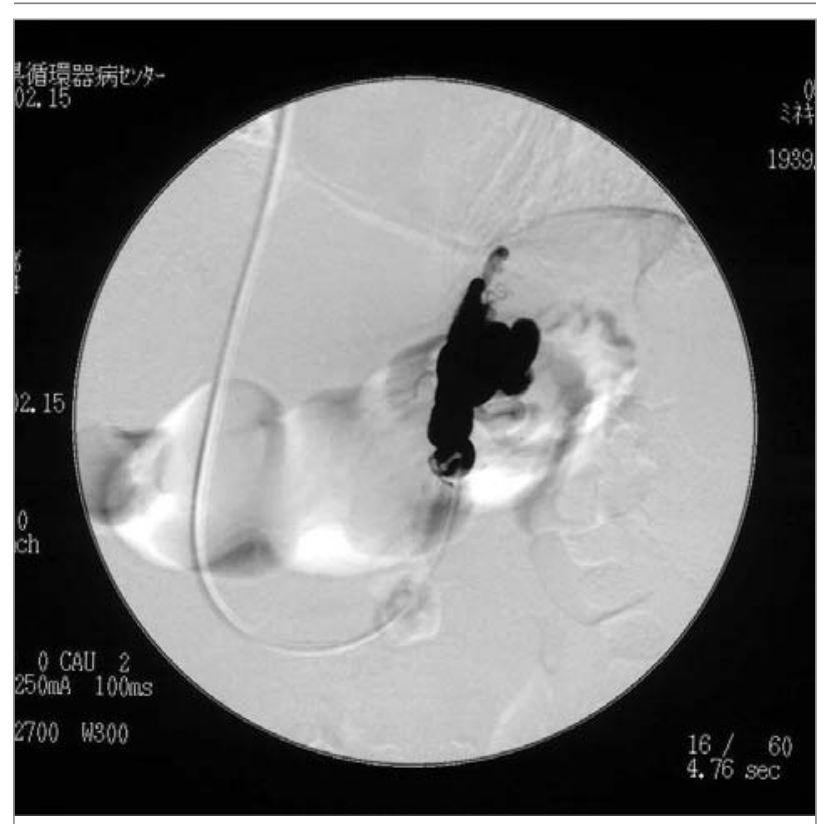

Figure 3a. Retrograde venography

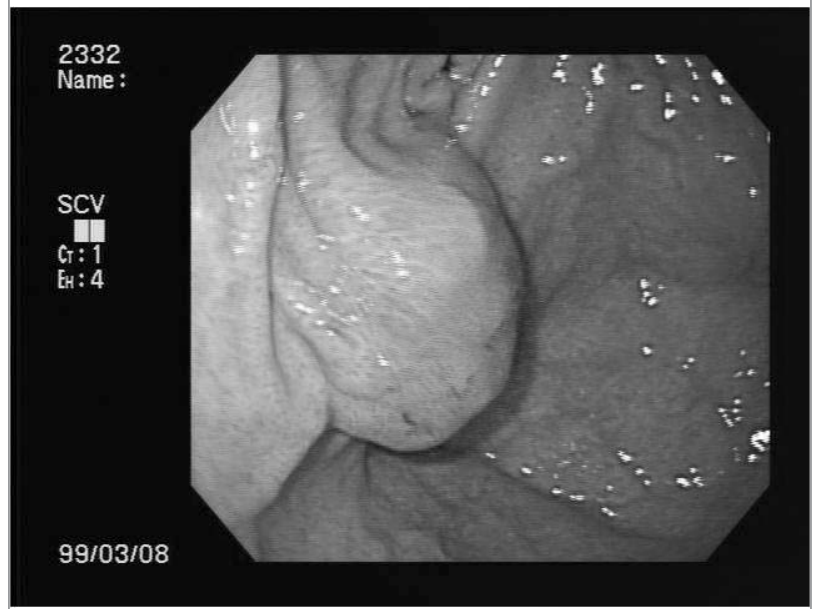

Figure $3 b$. Before B-RTO

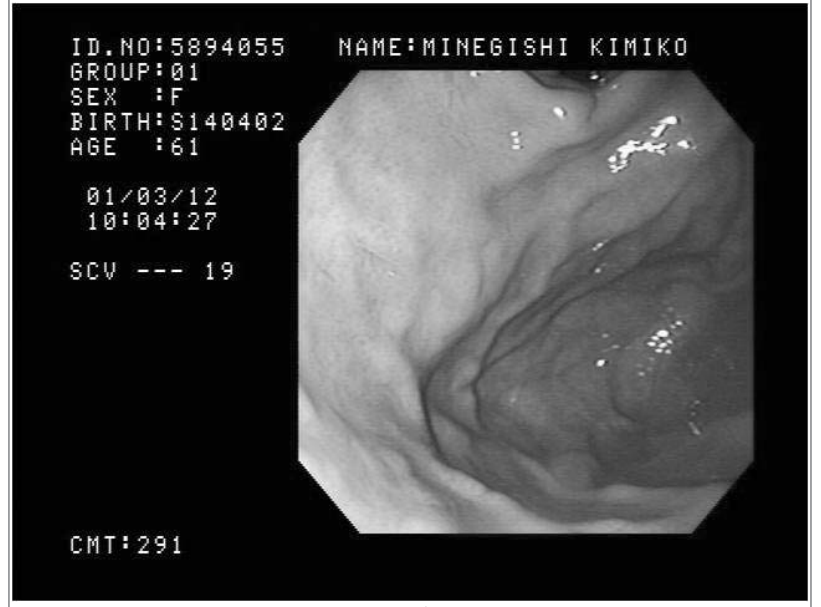

Figure 3c. After B-RTO

Figure 3: B-RTO for GV in cirrhotic patient (non B non C), 59year-old female 
et al. reported the efficacy of emergency B-RTO and reported that hemostasis was achieved in $100 \%$ of the patients. ${ }^{59}$ A prospective randomized study with a large number of patients will be necessary to determine the appropriate application of B-RTO for GV patients.

\section{SURGERY}

Surgical variceal decompression means producing a portal systemic shunt that diverts portal blood flow to reduce portal pressure. ${ }^{60-63}$ Hepatic encephalopathy and liver failure are major complications of this method. Furthermore, it has the disadvantage of high mortality in patients with advanced liver disease, particularly in an emergency setting. ${ }^{64}$ In fact, the application of surgical treatment is decreasing according to the development of the less invasive endoscopic and/or IVR techniques. Still, it may be an option for limited numbers of GV patients who are not eligible for other therapies and have preserved liver function.

\section{CONCLUSION}

Recent advancements in medical technologies have resulted in the development of diagnosis and effective treatments for GV. However, some problems in the clinical management of GV still exist. First, risk factors and hemodynamic backgrounds for GV bleeding have not been fully clarified yet. Second, prospective RCT is necessary to prove whether prophylactic treatment for FV is appropriate or not. Third, the role of percutaneous transhepatic obliteration (PTO) and/or partial splenic embolization (PSE) for treatment of GV should be established, because for certain reasons there are still some cases difficult to complete by B-RTO or TIPS. It is expected that these problems will be resolved in the near future.

\section{REFERENCES}

1. Bosch J, Abraldes JG, Groszmann R. Current management of portal hypertension. J Hepatol 2003; 38: S54-S68.

2. Sarin SK, Lahoti D, Saxena SP. Prevalence, classification and natural history of gastric varices: a long-term follow-up study in 568 portal hypertension patients. Hepatology 1992; 16: 1343-9.

3. Kim T, Shijo H, Kokawa H. Risk factors for hemorrhage from gastric fundal varices. Hepatology 1997; 25: 307-12.

4. Ryan BM, Stockbrugger RW, Ryan JM. A pathophysiologic, gastroenterologic, and radiologic approach to the management of gastric varices. Gastroenterology 2004; 126: 1175-89.

5. Lubel JS, Angus PW. Modern management of portal hypertension. Intern Med J 2005; 35: 45-9.

6. Williams SG, Westaby D. Management of variceal haemorrhage. BMJ 1994; 308: 1213-17.

7. Sarin SK, Kumar A. Gastric varices: profile, classification, and management. Am J Gastroenterol 1989; 84: 1244-1249.

8. The Japan Society for Portal Hypertension. The general rules for study of portal hypertension. $2^{\text {nd }}$ ed. 2004: 37-50.

9. Madsen MS, Petersen TH, Sommer H. Segmental portal hypertension. Ann Surg 1986; 204: 72-77.

10. Sutton JP, Yarborough DY, Richards JT. Isolated splenic vein occlusion. Arch Surg 1970; 100: 623-626.

11. Evan GR, Yellin AE, Weaver FA. Sinistral (left-sided) portal hypertension. Am Surg 1990; 56: 758-763.

12. Suhocki PV, Berend KR, Trotter JF. Idiopathic splenic vein stenosis: a cause of gastric variceal hemorrhage. South Med J 2000; 93: 812-814.

13. Sato T, Yamazaki K, Toyota J. Gastric varices with splenic vein occlusion treated by splenic arterial embolization. J Gastroenterol 2000; 35: 290-295.

14. Arakawa M, Masuzaki T, Okuda K. Pathomorphology of esophageal and gastric varices. Semin Liver Dis 2002; 22: 73-82.

15. Widrich WC, Srinivasan M, Semine MC. Collateral pathways of the left gastric vein in portal hypertension. AJR Am J Roentgenol 1984; 142: 375-382.

16. Takashi M, Igarashi M, Hino S. Esophageal varices: correlation of left gastric venography and endoscopy in patients with portal hypertension. Radiology 1985; 155: 327-331.

17. Matsutani S, Furuse J, Ishii H. Hemodynamics of the left gastric vein in portal hypertension. Gastroenterology 1993; 105: 513-518.

18. Watanabe K, Kimura K, Matsutani S. Portal hemodynamics in patients with gastric varices: a study in 230 patients with esophageal and/or gastric varices using portal vein catheterization. Gastroenterology 1988; 95: 434-40.

19. Kimura K, Ohto M, Matsutani S. Relative frequencies of portosystemic pathways and renal shunt formation through the "posterior" gastric vein: portographic study in 460 patients. Hepatology 1990;12: 725-8.

20. Chao Y, Lin HC, Lee FY. Hepatic hemodynamic features in patients with esophageal or gastric varices. J Hepatol 1993; 19: 85-9.

21. Tripathi D, Therapondos G, Jackson E. The role of the transjugular intrahepatic portosystemic stent shunt (TIPSS) in the management of bleeding gastric varices: clinical and 
haemodynamic correlations. Gut 2002; 51: 270-4.

22. Trudeau W, Prindiville T. Endoscopic injection sclerosis in bleeding gastric varices. Gastrointest Endosc 1986; 32: 2648.

23. Sarin SK, Sachdev G, Nanda R. Endoscopic sclerotherapy in the treatment of gastric varices. Br J Surg 1988; 75: 747-50

24. Terés J, Cecilia A, Bordas JM. Esophageal tamponade for bleeding varices. Controlled trial between the SengstakenBlakemore tube and the Linton-Nachlas tube. Gastroenterology 1978; 75: 566-9.

25. Hosking SW, Johnson AG. Gastric varices: a proposed classification leading to management. Br J Surg 1988; 75: 1956

26. Tripathi D, Ferguson JW, Therapondos G. Review article: recent advances in the management of bleeding gastric varices. Aliment Pharmacol Ther 2006; 24: 1-17.

27. Akiyoshi $\mathrm{N}$, Shijo $\mathrm{H}$, Iida $\mathrm{T}$. The natural history and prognostic factors in patients with cirrhosis and gastric fundic varices without prior bleeding. Hepatol Res 2000; 17:145-55

28. D'amico G, Pagliaro L, Bosch J. The treatment of portal hypertension: a meta-analytic review. Hepatology 1995; 22 332-54.

29. Sarin SK, Jain AK, Jain M. A randomized controlled trial of cyanoacrylate versus alcohol injection in patients with isolated fundic varices. Am J Gastroenterol 2002; 97: 1010-5.

30. Greenwald BD, Caldwell SH, Hespenheide EE. N-2-butylcyanoacrylate for bleeding gastric varices: a United States pilot study and cost analysis. Am J Gastroenterol 2003; 98: 1982-8.

31. Akahoshi $\mathrm{T}$, Hashizume M, Shimabukuro R. Long-term results of endoscopic histoacryl injection sclerotherapy for gastric variceal bleeding. A 10-year experience. Surgery 2002; 131: S176-81.

32. Irisawa A, Obara K, Sato Yl. Adherence of cyanoacrylate which leaked from gastric varices to the left renal vein during endoscopic injection sclerotherapy: a histopathologic study. Endoscopy 2000; 32: 804-6.

33. Takeuchi M, Nakai Y, Syu A. Endoscopic ligation of gastric varices. Lancet 1996; 348: 1038.

34. Cipolletta L, Bianco MA, Rotondano G. Emergency endoscopic ligation of actively bleeding gastric varices with a detachable snare. Gastrointest Endosc 1998 ; 47: 400-3.

35. Shiha G, El-Sayed SS. Gastric variceal ligation: a new technique. Gastrointest Endosc 1999; 49: 437-441.

36. Lo GH, Lai KH, Cheng JS. A prospective, randomized trial of butyl cyanoacrylate injection versus band ligation in the management of bleeding gastric varices. Hepatology 2001; 33: $1060-4$.

37. Williams SG, Peters RA, Westaby D. Thrombin - an effective treatment for gastric variceal haemorrhage. Gut 1994; 35: 1287-9.

38. Przemioslo RT, McNair A, Williams R. Thrombin is effective in arresting bleeding from gastric variceal hemorrhage. Dig Dis Sci 1999; 44: 778-81.

39. Yoshida T, Harada T, Shigemitsu T. Endoscopic management of gastric varices using a detachable snare and simultaneous endoscopic sclerotherapy and O-ring ligation. J Gastroenterol Hepatol 1999; 14: 730-735.

40. Yoshida H, Onda M, Tajiri T. New techniques: combined endoscopic injection sclerotherapy and ligation for acute bleeding from gastric varices. Hepatogastroenterology 2002; 49:932-934.

41. Jalan R, Lui HF, Redhead DN. TIPSS 10 years on. Gut 2000; 46: $578-81$

42. Stanley AJ, Jalan R, Ireland HM. A comparison between gastric and oesophageal variceal haemorrhage treated with transjugular intrahepatic portosystemic stent shunt (TIPSS). Aliment Pharmacol Ther 1997; 11: 171-6.

43. Chau TN, Patch D, Chan YW. "Salvage" transjugular intrahepatic portosystemic shunts: gastric fundal compared with esophageal variceal bleeding. Gastroenterology 1998; 114: 981-7.

44. Barange K, Peron JM, Imani K. Transjugular intrahepatic portosystemic shunt in the treatment of refractory bleeding from ruptured gastric varices. Hepatology 1999; 30: 1139-43.

45. Sanyal AJ, Freedman AM, Luketic VA. The natural history of portal hypertension after transjugular intrahepatic portosystemic shunts. Gastroenterology 1997; 112: 889-98.

46. Ryan BM, Stockbrugger RW, Ryan JM. TIPS for gastric varices. Gut 2003; 52: 772

47. Mahadeva S, Bellamy MC, Kessel D. Cost-effectiveness of Nbutyl-2-cyanoacrylate (histoacryl) glue injections vs. transjugular intrahepatic portosystemic shunt in the management of acute gastric variceal bleeding. Am J Gastroenterol 2003; 98: 2688-93.

48. Kanagawa H, Miwa S, Kouyama H. A successfully treated case of fundic varices by retrograde transvenous obliteration with balloon. Nippon Shokakibyo Gakkai Zasshi (in Japanese) 1991; 88: 1459-62.

49. Chikamori F, Shibuya S, Takase Y. Transjugular retrograde obliteration (TJO) for gastric varices. Abdom Imaging 1996; 21: 299-303. 
50. Arai H, Abe T, Shimoda R. Emergency B-RTO for gastric varices. J Gastroenterology 2005; 40: 964-71.

51. Nishida N, Ninoi T, Kitayama Y. Selective B-RTO of gastric varix with preservation of major portacaval shunt. AJR Am J Roentgenol 2006 ; 186: 1155-7

52. Tanoue S, Kiyosue H, Matsumoto S. Development of new coaxial balloon catheter system for B-RTO. Cardiovasc Intervent Radiol 2006; 29: 991-6

53. Kanagawa H, Mima S, Kouyama H. Treatment of gastric fundal varices by balloon-occluded retrograde transvenous obliteration. J Gastroenterol Hepatol 1996; 11: 51-8.

54. Koito K, Namieno T, Nagakawa T. Balloon-occluded retrograde transvenous obliteration for gastric varices with gastrorenal or gastrocaval collaterals. AJR Am J Roentgenol 1996; 167: 1317-20.

55. Hirota S, Matsumoto S, Tomita M. Retrograde transvenous obliteration of gastric varices. Radiology 1999; 211: 349-56

56. Shimoda R, Horiuchi K, Hagiwara S. Short-term complications of retrograde transvenous obliteration of gastric varices in patients with portal hypertension: effects of obliteration of major portosystemic shunts. Abdom Imaging, 2005; 30: 306313

57. Ninoi T, Nishida N, Kaminou T. Balloon-occluded retrograde transvenous obliteration of gastric varices with gastrorenal shunt: long-term follow-up in 78 patients. AJR Am J Roentgenol 2005; 184: 1340-1346.

58. Akahana T, Iwasaki T, Kobayashi N, Chages. Changes in liver function parameters after occlusion of gastrorenal shunts with balloon-occluded retrograde transvenous obliteration. Am J Gastroenterol 1997; 92: 1026-30

59. Arai H, Abe T, Shimoda R. Emergency balloon-occluded retrograde transvenous obliteration for gastric varices. J Gastroenterol 2005; 40: 964-71.

60. Grace ND, Groszmann RJ, Garcia-Tsao G. Portal hypertension and variceal bleeding: An AASLD single topic symposium. Hepatology 1998; 28: 868-880

61. Henderson JM, Nagle A, Curtas S. Surgical shunts and tips for variceal decompression in the 1990s. Surgery 2000; 128: $540-7$.

62. Orozco H, Mercado MA, Granados GJ. Selective shunts for portal hypertension: current role of a 21-year experience. Liver Transpl Surg 1997; 3: 475-80.

63. Thomas PG, D'Cruz AJ. Distal splenorenal shunting for bleeding gastric varices. Br J Surg 1994; 81: 241-4.

64. Krahenbuhl L, Seiler CA, Buchler MW. Variceal hemorrhage in portal hypertension: role of surgery in the acute and elective situation. Schweiz Med Wochenschr 1999; 129: $631-8$. 